\title{
The Representation of Ethics and Knowledge Organization in the WoS and LISTA Databases
}

\author{
Daniel Martínez-Ávila*, José Augusto Chaves Guimarães**, \\ Fabio Assis Pinho***, Melodie J. Fox**** \\ *Department of Information Science, São Paulo State University - UNESP, \\ Av. Hygino Muzzi Filho, 737, Marília (17525-900) - São Paulo - Brazil, \\ $<$ dmartinezavila@marilia.unesp.br> \\ **Department of Information Science, São Paulo State University - UNESP, \\ Av. Hygino Muzzi Filho, 737, Marília (17525-900) - São Paulo - Brazil, \\ <guima@marilia.unesp.br> \\ ***Department of Information Science, Federal University of Pernambuco - \\ UFPE, Av. da Arquitetura s/n - Recife (50740-550) - Pernambuco - Brazil, \\ <fabiopinho@ufpe.br> \\ ****School of Information Studies, University of Wisconsin-Milwaukee, NQBB, \\ 3rd Floor, 2025 E Newport, Milwaukee, WI 53211, U.S.A., \\ $<$ melodie.fox@gmail.com>
}

Daniel Martínez-Ávila holds a PhD from University Carlos III of Madrid, Spain. He is an assistant professor at São Paulo State University (UNESP), Marilia, Brazil. He also collaborates with the Institute for Gender Studies (IEG) at University Carlos III of Madrid, Spain.

José Augusto Chaves Guimarães is a professor at the Graduate School of Information Science, São Paulo State University-UNESP (Marília-Brazil). His research and teaching interests are epistemology of knowledge organization, knowledge organization ethics, archival knowledge organization, and domain analysis.

Fabio Assis Pinho is an associate professor in the Department of Information Science at the Federal University of Pernambuco, Recife-PE, Brazil. He received his master's in information science in 2006, and his PhD in information science in 2010, both from the São Paulo State University, Marilia-SP, Brazil. His research interests lie in the broad area of knowledge organization and representation, specially the ethical issues in knowledge organization. His bibliographical production is registered at http://lattes.cnpq.br/4220711855480007.

Melodie J. Fox holds a PhD in information studies, focusing on knowledge organization, with a minor in gender studies, from the University of Wisconsin-Milwaukee's iSchool, the School of Information Studies, where she was also a member of the KOrg Knowledge Organization Research Group. She also holds an MLIS, also from UWM and an MA in English from the University of Illinois at Chicago. She currently serves as Reviews Editor for Knowledge Organization. Her research interests include the social consequences of classification, ethics in knowledge organization, epistemology, ontology (in the philosophical sense) and gender studies.

Martínez-Ávila, Daniel, Chaves Guimarães, José Augusto, Assis Pinho, Fabio, Fox, Melodie J. The Representation of Ethics and Knowledge Organization in the WoS and LISTA Databases. Knowledge Organization. 42(5), 269-275. 33 references.
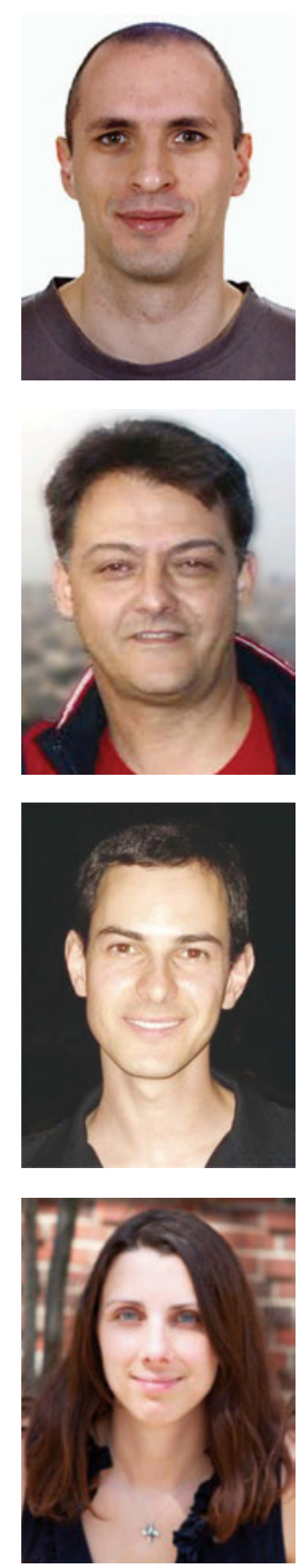
D. Martínez-Ávila, J. A. Chaves Guimarães, F. Assis Pinho, M. J. Fox. The Representation of Ethics and Knowledge Organization ...

Abstract: A naïve user seeking introductory information on a topic may perceive a domain as it is shown by the search results in a database; however, inconsistencies in indexing can misrepresent the full picture of the domain by including irrelevant documents or omitting relevant ones, sometimes inexplicably. A bibliometric analysis was conducted on the domain of ethics in knowledge organization in the World of Science (WoS) and Library, Information Science \& Technology Abstracts (LISTA) databases to discern how it is being presented by search results in those databases and to attempt to determine why inconsistencies occurred.

Received: 17 July 2015; Accepted 17 July 2015

Keywords: knowledge organization, ethics, information, databasesWoS, LISTA

\subsection{Introduction}

Ethics in knowledge organization $(\mathrm{KO})$ has become a growing concern in both practice and research. Examples from practice can be found in the American Library Association's Code of Ethics (2008), the 2012 International Federation of Library Assocations and Institutions Code of Ethics for Librarians and other Information Workers, and in archival codes of ethics and principles from around the world (Rego et al. 2014). The two conferences and proceedings on ethics in knowledge organization in 2009 and 2012 are further indications of academic interest and scholarly activity on the topic. These contributions generated a research stream of bibliographic publications that should be readily available for access through databases such as the Web of Science (WoS). As a legacy for future research and expansion of the subdomain of ethics in $\mathrm{KO}$, scholars and practitioners interested in getting introduced into the tradition will access these databases and be influenced by the perception of the domain as presented by search results.

As a systematized re-creation of a research process, bibliometric studies can reveal snapshots of the perception of a domain's research patterns and also warn of potential ethical problems of the silencing or misrepresentation of the knowledge in that particular domain. This paper describes and analyzes the results of our bibliometric analysis studying the representation of ethics and $\mathrm{KO}$ in WoS and Library, Information Science \& Technology Abstracts (LISTA) databases. The motivation of the study is to re-create how an average or naïve user might perceive the topic of knowledge organization and ethics through the search results in these two common research tools. We aim to highlight how the omissions and insufficiencies of these databases provide an incomplete picture when superficially researching these topics.

\subsection{Methodology}

The use of bibliometrics and/or citation analysis to study the conformation of a domain, especially $\mathrm{KO}$, has been recommended and used by Hjørland (2002, 2012, 2013a),
Smiraglia (2008, 2011, 2013, 2014), Guimarães et al. (2012), Graf and Smiraglia (2014), and Beak et al. (2013a; 2013b). As Hjørland (2002, 436) puts it, "it is empirical and based on detailed analysis of connections between individual documents." The retrieved documents and omissions revealed by the databases, i.e. the system's side, is one focus of our research, with content analysis, i.e. the user's side, on the other. This method has been previously used in domain-analytical studies (e.g. Guimarães et al. 2012; Guimarães et al. 2014). The combination of bibliometric analysis, along with a specific type of content analysis and discourse analysis has also been used, for instance, by Mayor and Robinson (2014).

WoS was selected for its role as an important and prestigious resource, and sometimes the first and only tool, for research and the evaluation of science. Thus, the representation of the domain (ethics and KO) is shaped by the high standards for indexing and organization of the domain as an ontological representation (or misrepresentation). Several studies have pointed out the problems of online bibliographic products for bibliometric/informetric studies (e.g., Hood and Wilson, 2003), and more specifically for the WoS in aspects such as impact factor (Lange 2001), institutional affiliations (García-Zorita et al. 2006), time (delay) of indexing (Falagas et al. 2008), language biases in the coverage of the Science Citation Index (van Leeuwen et al. 2001), and journal coverage (The PLoS Medicine Editors 2006), especially regarding bias towards the country of origin of the journals (e.g., Paris et al. 1998; Rey-Rocha et al. 1999; Andersen 2000; Fernández-Cano and Bueno 2002; Sidiropoulos and Manolopoulos 2005).

To complement WoS, and to overcome some of the most important limitations (e.g. the omission of Cataloging \& Classification Quarterly, the journal that published the proceedings of the first conference on ethics in knowledge organization), we also analyzed LISTA, thus sidestepping some deliberate omissions of materials on ethics and knowledge organization due to criteria such as coverage quotas and inclusion of unrelated disciplines (discussed below). In addition, LISTA allows searching all text, a feature that is not available in the WoS (it only allows searching the Title, Abstract, Author Keywords, and 
D. Martínez-Ávila, J. A. Chaves Guimarães, F. Assis Pinho, M. J. Fox. The Representation of Ethics and Knowledge Organization ...

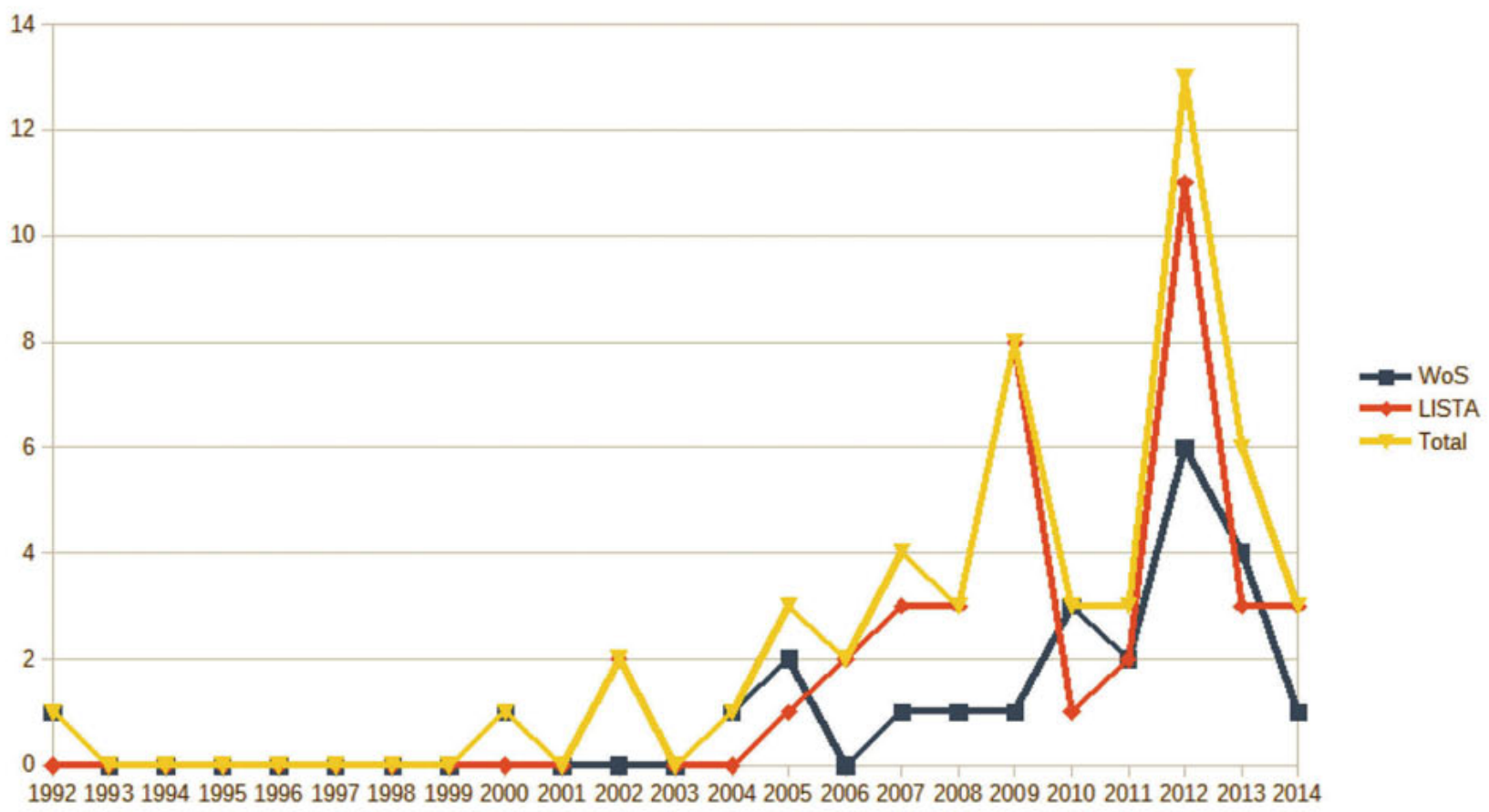

Figure 1: Frequencies of publications per year

Keywords Plus ${ }^{\circledR}$ fields). Other prestigious databases such as Scopus were also discarded for different reasons. Although it is said that Scopus is "unbiased" (Scopus 2015) and offers an overall wider journal range than WoS, it has also been pointed out that it is limited to more recent articles compared to WoS, whose indexed and archived records go back to 1900 (Falagas et al. 2008, 338-9). In this vein, we thought that the inclusion of LISTA would be sufficient, a priori, to overcome some of the specific coverage problems in $\mathrm{WoS}$, as well as these two databases seem to be the first common options for many researchers in our area.

Aware that many ethical works in KO do not actually use the word "ethics" in them, or that the term may not appear in the main fields used in the indexing process, we also searched for related terms that might come to the mind of the users or indexers such as "moral" and included spelling variants and near-synonyms such as "information organization," "knowledge organisation," and “information organisation." For the WoS (all databases), the retrieval profile was:

TOPIC: (ethic* OR moral*) AND TOPIC: ("information organization" OR "knowledge organization" OR “information organisation" OR "knowledge organisation")

Timespan: All years. Search language $=$ Auto
In LISTA, the retrieval profile was: ("knowledge organization" OR "information organization" OR "knowledge organisation" OR "information organisation") AND (ethic* OR moral*). We searched both databases on February 2 nd 2015, covering all the years and articles indexed by the databases. The choice of these databases and terms, purposively excluding other more $\mathrm{KO}$-oriented resources such as the ISKO proceedings, which are not indexed, was meant to re-create the results a non-specialized/general researcher would get as a first contact with the topics by only using these common databases.

\subsection{Results}

We retrieved 24 references from the WoS and 39 references from LISTA that were indexed or responded to a search on knowledge organization and ethics by both. This makes 53 references in total, excluding 10 overlapping references. On the other hand, a relatively high number of unique references (14 and 29) were retrieved from each database, which means that not all papers responding to those retrieval profiles have been unanimously indexed by both databases. Although both profiles are not technically equivalent, they both are meant to represent the same information need according to the possibilities of the databases.

Figure 1 shows the frequency of publications per year for each database and the total results. In the totals, two 
D. Martínez-Ávila, J. A. Chaves Guimarães, F. Assis Pinho, M. J. Fox. The Representation of Ethics and Knowledge Organization ...

\begin{tabular}{|l|c|c|}
\hline Source & Freq & $\%$ \\
\hline Knowledge Organization & 10 & $\mathbf{4 1 , 6 7}$ \\
\hline $\begin{array}{l}\text { 11th International ISKO Conference, Rome, } \\
\text { Italy, Feb 23-26, 2010 }\end{array}$ & 2 & $\mathbf{8 , 3 3}$ \\
\hline International Journal of Medical Informatics & 2 & $\mathbf{8 , 3 3}$ \\
\hline Community Development Journal & 1 & $\mathbf{4 , 1 7}$ \\
\hline $\begin{array}{l}\text { 8th UICEE Annual Conference on Enginee- } \\
\text { ring Education, Kingston, Jamaica, Feb 07- } \\
\text { 11,2005 }\end{array}$ & 1 & $\mathbf{4 , 1 7}$ \\
\hline $\begin{array}{l}\text { 9th World Multi-Conference on Systemics, } \\
\text { Cybernetics and Informatics, Orlando, FL, Jul } \\
\text { 10-13, 2005 }\end{array}$ & 1 & $\mathbf{4 , 1 7}$ \\
\hline International Classification & 1 & $\mathbf{4 , 1 7}$ \\
\hline Journal of Documentation & 1 & $\mathbf{4 , 1 7}$ \\
\hline $\begin{array}{l}\text { Journal of Professional Issues in Engineering Educa- } \\
\text { tion and Practice }\end{array}$ & 1 & $\mathbf{4 , 1 7}$ \\
\hline Library Quarterly & 1 & $\mathbf{4 , 1 7}$ \\
\hline $\begin{array}{l}\text { Life Science Journal-Acta Zhengzhou University } \\
\text { Overseas Edition }\end{array}$ & 1 & $\mathbf{4 , 1 7}$ \\
\hline Systemic Practice and Action Research & 1 & $\mathbf{4 , 1 7}$ \\
\hline $\begin{array}{l}\text { The Journal of Korean Association of Computer } \\
\text { Education }\end{array}$ & 1 & $\mathbf{4 , 1 7}$ \\
\hline Total & 24 & 100 \\
\hline
\end{tabular}

Table 1: Frequencies and percentages of sources retrieved from the WoS

peaks of publications occur in 2009 and 2012 (coinciding with the conference proceedings on ethics in knowledge organization). However, the 2009 peak only occurs in LISTA, since the proceedings of the 2009 conference were published in Cataloging \& Classification Quarterly, which is not indexed by WoS. Of these proceedings, 4 articles were included, while 2 articles were omitted even by LISTA. As for the 2012 proceedings, published in Knowledge Organization, which is indexed by both databases, only 3 papers were retrieved from both, 5 were retrieved exclusively from LISTA, and 5 articles were omitted by both databases.

Nearly all of the 53 papers are written in English, with one paper exclusively retrieved from the WoS in Korean, and one paper in Spanish and one in Portuguese exclusively retrieved from LISTA. Although this might be interpreted as geographic bias, several authors from Brazil, Spain and other countries author papers in English. The most productive authors, according to this picture, are José Augusto Guimarães and Joseph Tennis (2 papers each) for the WoS results, and Donald Hawkins (2 papers) for the LISTA results. Every other author in both databases only appears in one paper. The total list of results also presents these three authors (Guimarães, Hawkins, and Tennis) with only two papers and a long tail of authors with only one paper. The co-authorship index for the WoS is 1.67 (40 authors / 24 documents), for LISTA is

\begin{tabular}{|l|c|c|}
\hline Source & Freq & $\%$ \\
\hline Knowledge Organization & 17 & 43,59 \\
\hline Information \& Organization & 6 & 15,38 \\
\hline Cataloging \& Classification Quarterly & 4 & 10,26 \\
\hline Journal of Documentation & 3 & 7,69 \\
\hline Information Today & 2 & 5,13 \\
\hline Scire & 2 & 5,13 \\
\hline Education for Information & 1 & 2,56 \\
\hline Indexer & 1 & 2,56 \\
\hline Information Studies & 1 & 2,56 \\
\hline Journal of Information Ethics & 1 & 2,56 \\
\hline Library Quarterly & 1 & 2,56 \\
\hline Total & 39 & 100 \\
\hline
\end{tabular}

Table 2: Frequencies and percentages of sources retrieved from LISTA

1.54 (60 authors / 39 documents), and for the total 1.58 (84 authors / 53 documents).

The most frequent sources retrieved from the WoS (see Table 1) are ISKO sources: Knowledge Organization (10 papers), and the International ISKO Conference Proceedings of 2010, Rome (2 papers). Only the recent international ISKO Conference Proceedings are being indexed by the WoS, while the old ones and the different regional ISKO chapters' proceedings are still omitted (none appear in LISTA). The most frequent sources retrieved from LISTA are in Table 2. Although Knowledge Organization is indexed by both databases, LISTA retrieves 7 more papers overall, while only 8 papers are retrieved from both databases. LISTA also retrieves 2 extra Journal of Documentation articles, in spite of being indexed by both databases. Some of these more frequent sources retrieved from LISTA, such as Cataloging \& Classification Quarterly and Scire, are knowledge organization specific journals that are not indexed by the WoS. Overall, the most frequent sources in the "whole picture" (see Table 3) are Knowledge Organization, Information \& Organization, Cataloging \& Classification Quarterly and Journal of Documentation.

Of the 13 sources retrieved from the WoS, only 3 sources are also indexed by LISTA (Knowledge Organization, Journal of Documentation, and Library Quarterly) and thus include papers (12) that should be potentially retrievable from both databases. On the other hand, of the 11 sources retrieved from LISTA, 4 sources are also indexed by the WoS, i.e., the three aforementioned overlapping sources plus Information and Organization (although the 3 earliest papers published in 2006 and 2002 are not indexed). This makes 24 out of 39 papers retrieved from LISTA that are potentially retrievable from both databases. The sum of the papers potentially retrievable from both data- 
D. Martínez-Ávila, J. A. Chaves Guimarães, F. Assis Pinho, M. J. Fox. The Representation of Ethics and Knowledge Organization ...

\begin{tabular}{|l|c|c|}
\hline Source & Freq & $\%$ \\
\hline Knowledge Organization & 19 & 35,85 \\
\hline Information \& Organization & 6 & 11,32 \\
\hline Cataloging \& Classification Quarterly & 4 & 7,55 \\
\hline Journal of Documentation & 3 & 5,66 \\
\hline $\begin{array}{l}\text { 11th International ISKO Conference, Rome, } \\
\text { Italy, Feb 23-26, 2010 }\end{array}$ & 2 & 3,77 \\
\hline Information Today & 2 & 3,77 \\
\hline International Journal of Medical Informatics & 2 & 3,77 \\
\hline Scire & 2 & 3,77 \\
\hline Community Development Journal & 1 & 1,89 \\
\hline $\begin{array}{l}\text { 8th UICEE Annual Conference on Enginee- } \\
\text { ring Education, Kingston, Jamaica, Feb 07-11, } \\
\text { 2005 }\end{array}$ & 1 & 1,89 \\
\hline $\begin{array}{l}\text { Pth World Multi-Conference on Systemics, Cy- } \\
\text { bernetics and Informatics, Orlando, FL, Jul 10- } \\
\text { 13, 2005 }\end{array}$ & 1 & 1,89 \\
\hline Education for Information & 1 & 1,89 \\
\hline Indexer & 1 & 1,89 \\
\hline Information Studies & 1 & 1,89 \\
\hline International Classification & 1 & 1,89 \\
\hline Journal of Information Ethics & 1 & 1,89 \\
\hline $\begin{array}{l}\text { Journal of Professional Issues in Engineering Educati- } \\
\text { on and Practice }\end{array}$ & 1 & 1,89 \\
\hline Library Quarterly & 1 & 1,89 \\
\hline $\begin{array}{l}\text { Life Science Journal-Acta Zhengzhou University Over- } \\
\text { seas Edition }\end{array}$ & 1 & 1,89 \\
\hline Systemic Practice And Action Research & 1 & 1,89 \\
\hline $\begin{array}{l}\text { The Journal of Korean Association of Computer Edu- } \\
\text { cation }\end{array}$ & 1 & 1,89 \\
\hline Total & 53 & 100 \\
\hline
\end{tabular}

Table 3: Frequencies and percentages of total sources

bases is 26 out of 53 ; however, as pointed out before, only 10 overlapping references result, with 16 references omitted by one of the databases (in addition to the references that might be omitted by both databases).

Two references omitted by LISTA are papers published in the same issue of Knowledge Organization. No logical reason for the omission of these articles based on the retrieval profile could be found, since both articles are included in the database and other articles from the same journal with similar characteristics were retrieved. In fact, one presents the terms "ethics" and "knowledge organization" in the abstract and text and "ethics," "values," and "morality" in its title, and the other presents the expression "ethical knowledge organization" in the abstract and text too.

The references omitted only by WoS are 14 . Nine of these references were published in Knowledge Organization.
Two do not include the terms "ethic*" or "moral*" as used this study, but rather their authors' names include the string "moral" (Raquel del Moral and Miguel A. Morales-Arroyo respectively), thus the omission seems to be justified; one includes the terms "ethics" and "knowledge organization" in the abstract so it should be retrieved; however that particular issue of the journal does not seem to be indexed; one is indexed by WoS and includes the term "knowledge organization" and the roots "ethic*" and "moral*," however most of these appear in the text with only "ethical" is in the abstract, thus making it irretrievable from WoS; the rest of the Knowledge Organization references are all part of the special issue for the 2nd Milwaukee Conference on Ethics in Information Organization so they are assumed to be related in spite of not being retrieved. One includes the term "ethical" in the abstract and text, and "ethics" in the title, but "information organization" only in the text; one includes the terms "ethics" in the title, abstract and text, but "information organization" only in the text; one includes the terms "ethics" in the title, abstract and text, but no version of "knowledge organization;" one includes "ethics" or "ethical" in the title, abstract and text, but no version of "knowledge organization;" and one includes the term "ethical" in the abstract and text, but "knowledge organization" only in the text. All these references would have been retrieved if the name of the source was considered (being published in a journal called Knowledge Organization should imply a connection with knowledge organization); however, WoS, contrary to LISTA, does not consider this criterion. Thus, WoS omitted all references published in Information \& Organization (even when they are included in the database). However, although one included the term "morale," another included the term "ethics," and yet another included the terms "ethically" and "morally" in the abstract, none of the papers include any version of the phrase "knowledge organization." The second part of the query in LISTA seems to match the title of the journal and thus these omissions by the WoS might be justified. Similarly, the omission of the references that were published in the Journal of Documentation present the terms "moral" or "ethics" in the abstract, but no version of "knowledge organization" outside the body of the text, thus making the retrieval from WoS impossible according to the profile.

It seems hard, if not impossible, to determine all the works that are being omitted from both databases. This aspect is more problematic when working in an unstructured space such as the World Wide Web, but even when working with databases the burden is not only in the query/retrieval profile but also in the representation of the records and the features/decisions of the databases to match those queries. In this vein, we consider that our re- 
D. Martínez-Ávila, J. A. Chaves Guimarães, F. Assis Pinho, M. J. Fox. The Representation of Ethics and Knowledge Organization ...

trieval profiles seem to be plausible and even acceptable for a user initiating into the topic through these databases (given the technical possibilities of the databases). The silenced references might never be guessed without help of experts or other specialized tools (and some of them would be really relevant).

Finally we analyzed a sample of additional omissions, beginning with rest of the papers from the two conferences on ethics in knowledge organization: in one the term "ethical" is included in the abstract, but no version of "knowledge organization;" three include the terms "ethical" and "knowledge-organization" or "knowledge organization" in the text, but not in the title, abstract or keywords; two do not include the strings "ethic" or "moral;" and one only includes the term "ethical" in the text, and no version of "knowledge organization." Other examples of papers on ethics and knowledge organization that are omitted include papers that are indexed by both databases but do not include all the required terms in the title, abstract or keywords; and two more that both include in the title the terms "ethical" and "knowledge representation and organization," but probably are not retrieved because the words "knowledge" and "organization" are separated in the string (despite a similar meaning). Another omitted paper presents the terms "ethical" and "knowledge organization" in its title, but because it is published in the ISKO international conference proceedings of 2002 it is not indexed by the WoS and LISTA (only the latest international ISKO conference proceedings are being indexed by the WoS, beginning with 2012). Finally, books are omitted because they are not usually indexed by academic databases such WoS and LISTA. It should be noted that all of the omitted papers described here are indexed by the Knowledge Organization Literature database.

\subsection{Conclusions}

Many of the problems in the perception of "knowledge organization" and "ethics" through common generalist databases such as the WoS and LISTA seem to be rooted in indexing and retrieval problems. In 1997, Frederick C. Thorne noted, "it is of critical importance whether any specific journal or paper is systematically included in research reviews and abstract journals if it is to receive wide notice at all. Many authors do not read original sources systematically, but depend on reviews and abstracts. In the past, significant journals and articles have not been included in reviews and abstract journals either due to error or deliberate omission" (1159). More recently, authors have pointed out bias and subjectivity in algorithms and systems such as Google (e.g. Segev 2009; Hjørland 2013b). Similarly, algorithms, options, and decisions in databases also affect the way users perceive a domain. Omissions based on indexing policies (such as coverage and format) and other omissions (such as the misrepresentation of contents) can affect the perception of the concepts and scientific configuration of sensitive topics such as "knowledge organization" and "ethics." To overcome these problems, some more specific databases, covering a wider range of materials, and maintained by international experts in the field (such as the Knowledge Organization Literature database) seem to be a good resource for the research initiation in specialized topics.

\section{References}

American Library Association. 2008. Code of Ethics of the American Library Association. http://www.ala.org/ advocacy/proethics/codeofethics/codeethics.

Andersen, Heine. 2000. Influence and reputation in the Social Sciences: how much do researchers agree? Journal of documentation 56: 674-92.

Beak, Jihee, Jeanette Glover, Daniel Martínez-Ávila and Suellen Oliveira Milani. 2013. "International Comparative Domain Analysis in Knowledge Organization Research Topics in Four Countries - Brazil, South Korea, Spain and the United States." In Proceedings from North American Symposium on Knowledge Organization, Vol. 4. University of Wisconsin-Milwaukee, edited by Richard P. Smiraglia. http://www.iskocus.org/NASKO2013pro ceedings/Beak_InternationalComparativeDomain Analysis.pdf.

Beak, Jihee, Jeanette Glover, Daniel Martínez-Ávila and Suellen Oliveira Milani. 2013. "International Comparative Study Analyzing Knowledge Organization Research Topics in Four Countries - Brazil, South Korea, Spain and United States." In iConference 2013 Proceedings: Data, Innovation, Wisdom, Scholarship in Action, edited by Linda Schamber, iSchools, 668-70. http://hdl. handle.net/2142/42081

Falagas, Matthew E., Eleni I. Pitsouni, George A. Malietzis, and Georgios Pappas. 2008. Comparison of PubMed, Scopus, Web of Science, and Google Scholar: strengths and weaknesses. The Faseb Journal. 22: 338-42.

Fernández-Cano, Antonio, and Ángel Bueno. 2002. Multivariate evaluation of Spanish educational research journals. Scientometrics 55: 87-102.

García-Zorita, Carlos, Carmen Martín-Moreno, M. Luisa Lascurain-Sánchez, and Elías Sanz-Casado. 2006. Brief communication Institutional addresses in the Web of Science: the effects on scientific evaluation. Journal of information science 32: 378-83.

Graf, Ann M., and Richard P. 2014. Race \& Ethnicity in the Encyclopedia of Milwankee: A Case Study in the Use of Domain Analysis. Knowledge Organization in the 21st Century: Between Historical Patterns and Future Prospects: 
D. Martínez-Ávila, J. A. Chaves Guimarães, F. Assis Pinho, M. J. Fox. The Representation of Ethics and Knowledge Organization ...

Proceedings of the Thirteenth International ISKO Conference 19-22 May 2014 Krakóm, Poland, ed., Wieslaw Babik. Würzburg, Germany: Ergon-Verlag, pp. 114-20.

Guimarães, José Augusto, Fabio A. Pinho, and Gustavo M. Ferreira. 2012. Relações teóricas da organização do conhecimento com as abordagens de catalogação de assunto, indexação e análise documental. Scire 18, no. 2: $31-41$.

Guimarães, José Augusto, Rodrigo de Sales, Daniel Martínez-Ávila, and Maíra Fernandes Alencar. 2014. The Conceptual Dimension of Knowledge Organization in the ISKO Proceedings Domain: A Bardian Content Analysis. In Knowledge Organization in the 21st Century: Between Historical Patterns and Future Prospects: Proceedings of the Thirteenth International ISKO Conference 19-22 May 2014 Krakón, Poland, ed., Wieslaw Babik. Würzburg, Germany: Ergon-Veralg, pp. 101-6.

Hjørland, Birger. 2002. Domain analysis in information science: Eleven approaches - traditional as well as innovative. Journal of documentation 58: 422-62.

Hjørland, Birger. 2012. Knowledge Organization = Information Organization? In Categories, Contexts and Relations in Knowledge Organization: Proceedings of the Twelfth International ISKO Conference 6-9 August 2012 Mysore, India, eds., A. Neelameghan, and K.S. Raghavan. Würzburg, Germany: Ergon-Verlag, pp. 8-14.

Hjørland, Birger. 2013a. Citation analysis: A social and dynamic approach to knowledge organization. Information processing and management 49: 1313-25.

Hjørland, Birger. 2013b. User-based and cognitive approaches to knowledge organization. Knowledge organization 40: 11-27.

Hood, William W., and Concepción S. Wilson. 2003. Informetric studies using databases: opportunities and challenges. Scientometrics 58: 587-608.

International Federation of Library Asssociations and Institutions. 2012. IFLA Code of Ethics for Librarians and other Information Workers. http://www.ifla.org/news/ ifla-code-of-ethics-for-librarians-and-other-informationworkers-full-version.

Lange, Lydia. L. 2001. The impact factor as a phantom. Is there a self-fulfilling prophecy effect of impact? Journal of Documentation 58 no.2: 175-84.

Mayor, Charlie, and Lyn Robinson. 2014. Ontological realism, concepts and classification in molecular biology:
Development and application of the gene ontology. Journal of documentation 70: 173-93.

Paris, Gianmarco, Giulio De Leo, Paolo Menozzi, and Marino Gatto. 1998. Region-based citation bias in science. Nature 396: 210.

The PLoS Medicine Editors. 2006. The Impact Factor Game. PLoS Med 3, no.6: e291.

Rego, Laura M. do, Andrieli P. Da Silva, Daniel MartínezÁvila, and Natalia B. Tognoli. 2014. Aspectos éticos na organização do conhecimento na prática profissional arquivística. Scire 20 no.2: 37-42.

Rey-Rocha, Jesús, M. José Martín-Sempere, Fernando Lopez-Vera, and Jesus Martinez-Frias. 1999. English versus Spanish in science evaluation. Nature 397 no.6714: 14.

Scopus. 2015. Content Overview | Elsevier. http://www.else vier.com/online-tools/scopus/content-overview.

Segev, Elad. 2009. Google and the digital divide: the biases of online knowledge. Cambridge, Chandos.

Sidiropoulos, Antonios, and Yannis Manolopoulos, 2005. A new perspective to automatically rank scientific conferences using digital libraries. Information processing and management 41: 289-312.

Smiraglia, Richard P. 2008. ISKO 10's Bookshelf: An Editorial. Knowledge organization 35: 187-91.

Smiraglia, Richard P. 2011. ISKO 11's Diverse Bookshelf: An Editorial. Knowledge organization 38: 179-86.

Smiraglia, Richard P. 2013. ISKO 12's Bookshelf — Evolving Intension: An Editorial. Knowledge organization 40: 3-10.

Smiraglia, Richard P. 2014. ISKO 13's Bookshelf: Knowledge Organization, the Science, Thrives-An Editorial. Knowledge organization 41: 343-56.

Thorne, Frederick C. 1977. The citation index: Another case of spurious validity. Journal of clinical psychology 33: 1157-61.

van Leeuwen, Thed N., Henk F. Moed, Robert J. W. Tijssen Martijn S. Visser, and Anthony F. J. van Raan. 2001. Language biases in the coverage of the Science Citation Index and its consequences for international comparisons of national research performance. Scientometrics 51: 335-46. 